\title{
Experimental research design in the study of electoral systems
}

\author{
Joshua Tucker and Dominik Duell
}

Prepared for the Oxford Handbook of Electoral Systems edited by Erik Herron, Robert Pekkanen, \& Matthew Shugart, New York: Oxford University Press, 2017.

\begin{abstract}
Understanding the effects of electoral systems is of great importance to both scholars and practitioners, and experimental research can be a valuable tool in pursuit of this goal. However, scholars need to think carefully about how to utilize experimental research, especially because the variation in electoral systems in which we are most interested - at the national level - is often impossible or unethical to manipulate. To inform how experiments and related methods of causal inference are then still able to facilitate investigations into the roots and consequences of electoral systems, we situate experimental research within a broader account of research design in the study of electoral systems, summarize existing experimental work, and discuss future avenues. We call for carefully crafting experimental tests in the laboratory and for using "naturally" occurring variation in existing institutions at lower levels of the electoral system.
\end{abstract}

Keywords: Laboratory Experiments, Field Experiments, Natural Experiments, Causal Inference, Identification.

\section{Introduction}

Experimental research has made broad inroads in the field of political science. The attractiveness of experimental research - by which we mean studies that utilize random assignment to treatment or attempt to find observational data that is in some way similar to random assignment - is clear: it allows scholars to more closely test causal arguments than many forms of observational analysis (Morton and Williams, 2010; Gerber and Green, 2012; Morton and Tucker 2014).

Electoral systems research, however, presents a paradoxical challenge to the rise of experimental research in political science. On the one hand, more than most topics we really need to know the causal impact of different electoral systems, because it is indeed possible to change electoral systems, and to do so quickly. If we, for example, believe that a certain electoral system is likely to reduce inequality, then politicians can act on our research and change the electoral rules in 
that manner, much more easily, than, for example, research results showing that "the country needs a higher GDP per capita" to achieve some political outcome or "the population should be better educated" in order to have a certain desirable result. Measuring the effect of education or wealth is of course important, but these are not factors that can be changed overnight; electoral rules, however can be. Research on electoral systems can have profoundly important policy consequences precisely because politicians can change electoral rules.

At the same time, the electoral rules in which we are most interested - national electoral rules - are practically impossible to ever randomly assign in an experiment, precisely because the effects of doing so would be too consequential. Indeed, some of the field's most prominent scholars seemed convinced that experimental research would play a small role in the field due to "practical and ethical impediments" (Lijphart, 1971, 684). As a result, most of the initial experimental work on electoral systems has been done in the lab. This in turn presents significant challenges to the development of the kind of research that can actually inform real world reforms, but the developing literature in the field also suggests new opportunities for constructive development of the field.

In the remainder of this chapter, we have three objectives. First, we aim to situate experimental research in the broader framework of research design in the field of electoral systems, which, as an editor of this volume has noted, "can now be regarded as a mature field" (Shugart, 2005, 25). We demonstrate that there is almost no experimental research in the landmark works on electoral systems, but that experimental research is appearing in more recent research at a greater frequency. Second, we summarize existing research in the study of electoral systems that employs an experimental framework, including lab, field, survey, and natural experiments. Finally, we conclude by outlining areas in which we believe the field can move forward in the future. 


\section{Research design in the study of electoral systems}

Our first task is to demonstrate where experimental analysis fits within the universe of research designs employed in the study of electoral systems. By "research design," we refer to the overall research plan, which in turn helps others to evaluate the validity of the study, to understand where the research fits into the knowledge previously accumulated on the topic - here electoral systems and to illustrate how to build on the study for future scholarship. ${ }^{1}$ Our goal here is simply to get a sense of how prevalent experimental research is in the overall field of the study of electoral systems.

Given the size of the field, of course, this necessitated some form of sampling strategy. To be as transparent (and replicable) as possible in this task, our initial foray into the literature was essentially guided by two simple algorithms. First, we employed Google Scholar to find the "seminal works" in the field. ${ }^{2}$ Then in order to get at more recent developments in the field, we went through each issue of the American Political Science Review, the American Journal of Political Science, World Politics, Comparative Political Studies, and Electoral Studies that was published in 2014 and identified every article we could find that featured research on electoral systems. ${ }^{3}$ While we recognize that such a strategy was not necessarily going to give us a truly representative sample of the literature in the field, we did feel it would do a good job of highlighting both the history and current directions of the field and, hopefully, allow us to make some useful observations about the

\footnotetext{
${ }^{1}$ In general, we care about research design because it lays out the concepts we use associated with the object of our study, provides the theory about the mechanism behind the social phenomena we are interested in, answers questions regarding how to gather, measure, and analyze data about this phenomena, and finally facilitates a dialog between concepts, theory, and data by each individual researcher but also across the field; this definition of research design loosely follows Gschwend and Schimmelfennig (2007).

${ }^{2}$ The exact algorithm we employed is described in more detail in the following section.

${ }^{3}$ Yes, we realize that by this point 2016 or even 2015 would have been better year to use, but the Oxford Handbook publishing process is a long one indeed. Nevertheless, the idea of picking a recent year to sample thoroughly to compliment the "classics" should not be dependent on it necessarily being the most recent year.
} 
state of the literature with respect to the prevalence of experimental research as a form of research design. Nevertheless, in view of the shortcomings of this approach, we supplemented our reading with other articles that caught our eye when reading the original set of papers and in the course of our own research.

\subsection{Seminal papers}

Our algorithm for finding "classic" works in the field was as followed. We began our inquiry with two seminal pieces in the study of electoral systems: Duverger's Political parties: Their organization and activity in the modern state and Lijphart's Electoral systems and party systems: A study of twenty-seven democracies, 1945-1990. We then located every article which features electoral systems as either an independent or dependent variable, has a citation count of at least 200 on Google Scholar, and cites either one (or both) of these seminal works.

In this collection, we found scholars primarily exploring the correlation of electoral systems with institutions, behaviors, and attitudes; in other words, treating electoral systems as independent variables. Electoral systems are linked to various outcomes: among others, the number of parties in political competition (Neto and Cox, 1997; Moser, 1999; Mozaffar, Scarritt and Galaich, 2003; Van de Walle, 2003); the coordination of voters on candidates with the potential to win elections (Cox, 1990); the spread of parties' positions in the system (Cox, 1990); the success of radical parties Norris (2005); the proportionality of electoral outcomes (Lijphart, 1994); the congruence of voters' preferences and policy outcomes (Powell, 2000) or voters' preferences and party positions (Golder and Stramski, 2010); public spending (Milesi-Ferretti, Perotti and Rostagno, 2002; Persson et al., 2007); corruption (Persson, Tabellini and Trebbi, 2003; Kunicova and Rose-Ackerman, 2005); economic policy and performance in general (Persson and Tabellini, 2005); frequency of divided government (Shugart, 1995); legislators' defection from the party line (Hix, 2004); the election of 
female candidates into public office (Jones, 1998; Norris, 2004; Schwindt-Bayer and Mishler, 2005); and turnout and voting behavior in general (Norris, 2004).

All 18 studies mentioned in the previous paragraph model electoral systems as an independent variable related to some political or economic outcome of interest. None of the works attempts causal identification of the effect of interest by employing an experimental (or quasi-experimental) framework. In general, with the exception of one purely theoretical study (Cox, 1990), these seminal papers all rely on observational data. ${ }^{4}$

\subsection{Papers published in 2014}

Next, we examine a population sample of publications in the American Political Science Review, the American Journal of Political Science, World Politics, Comparative Political Studies, and Electoral Studies in the year 2014, in order to gauge the prevalence of experimental research in the study of electoral systems more recently in top political science journals.

In the preceding section we argued that the modal research design in our collection of seminal papers in the field is an empirical study that tests theoretical implications with correlational evidence from observational studies, which is also the case in more recent research. Of all publications in the journals we reviewed, 95 explore electoral systems in some form: 88 are quantitative studies and explicitly empirically operationalize electoral systems as either an independent variable (79), as a dependent variable (Aytaç, 2014; Cantú, 2014; Curtice and Marsh, 2014), as both independent and dependent variables (Endersby and Towle, 2014; Miller, 2014), or

\footnotetext{
${ }^{4}$ For those interested in more detail regarding the operationalization of "electoral system," eight of the seminal papers operationalize the electoral system as a comparison between proportional and majoritarian systems, two consider district magnitude, and three look at the effect of downstream consequences of electoral systems on some other dependent variable of interest. The remainder test for the influence of multiple features of the electoral system at the same time.
} 
do not explicitly operationalize electoral institutions but make comparisons across institutions (Adams, Ezrow and Somer-Topcu, 2014; Clark and Leiter, 2014; Grossman and Woll, 2014; Spoon and Klüver, 2014); ${ }^{5}$ Two studies are formal theoretical (Cho, 2014; Gans-Morse, Mazzuca and Nichter, 2014) and one is normative (Murray, 2014); and, four studies discuss measurement issues (Krook, 2014; Otjes and Louwerse, 2014; Wawro and Katznelson, 2014; Wilson, 2014).

Of the 79 quantitative studies that explicitly model electoral systems, 19 include country fixed effects to acknowledge the influence of electoral systems on their variable of interest while not modeling this variation across systems. ${ }^{6}$ More generally, the modal research design, 35 out of 92 empirical studies, is still, as with the seminal papers described above, an empirical test of implications derived from either (formal or informal) theory or from the extant literature where conclusions are based on evidence delivered by conventional regression analysis. Another 35 studies implement refined statistical models, which account for some biases in the estimation of the relationship of interest and particular characteristics of the data: most frequently this means running a multilevel model (20 out of 35$)$, but also modeling temporal correlations, other features of the error structure, or the survival-data nature of the inquiry. Among the refined models, one article conducts a regression discontinuity design (Harada and Smith, 2014) and another one employs propensity score matching (Kolev, 2014).

However, 11 of the 92 empirical studies do employ some form of experimental design, in so far as they take advantage of a feature occurring in "nature" that induces randomness in the data

\footnotetext{
${ }^{5}$ These studies are looking at changes in vote share from one election to the other without acknowledging changes in electoral rules over time or do not model electoral rules at all.

${ }^{6}$ This is a point worth emphasizing. Country fixed effects are often included in studies as a sophisticated acknowledgement that there are important differences between countries, including, but obviously not limited to, electoral systems. While such fixed effects can control for these differences, they do not tell us anything at all about the actual effects of electoral systems. Moreover, country fixed effects may not even control for variation due to electoral rules when countries switch electoral rules over the period of study. And depending on the level of the electoral system, such rules may change more frequently than is often realized.
} 
generating process, ${ }^{7}$ run simulations (Weschle, 2014), conduct laboratory experiments (Corazzini et al., 2014; Blais, Pilet, Van der Straeten, Laslier and Héroux-Legault, 2014a), or run survey experiments (González Ocantos, Jonge and Nickerson, 2014; Baujard et al., 2014). The remaining studies are case studies (5), one paper using descriptive inference (1), and articles about research methodology (4). ${ }^{8}$ Overall, therefore, experimental research design - although now part of the study of electoral systems - remains a relatively small portion of that field.

\section{Experimental research in the study of electoral systems}

Given that (1) there is some experimental research in a field that (2) has in the past been dominated by more observational research and (3) largely remains so today, the next question to ask is what experimental research is contributing to the study of electoral systems. Here we break down our assessment of the state of the literature by different types of experimental research design.

\subsection{Laboratory experiments}

Investigations into the institutions and rules that govern politics as well as political attitudes and behaviors date back to the works of Condorcet in the 18th century, so it should come as no surprise that early experimental attempts in political science were concerned with testing implications of "ancient" formal theories (Kinder and Palfrey, 1993) and their modern extensions. Since the 1960s,

\footnotetext{
${ }^{7}$ A random separation of research units into "control" and "treatment" group is induced orthogonal to the variable of interest through, for example, change in the composition of a school cohort (Dinas and Stoker, 2014), gradual repeal of compulsory voting (Ferwerda, 2014), variation in assignment of names to positions on ballots (Chen et al., 2014), assignment of NGO field workers who then recommend decision-making rules to villagers (Grossman and Hanlon, 2014), or alphabetical assignment of voters do polling stations by name (Cantú, 2014); with a few more assumptions, the same can be said about comparing behavior across elections where in one election early voting rules were different (Finseraas and Vernby, 2014).

${ }^{8}$ Our sample of articles published in the year 2014 does not include publications in methods journals; the low number of methodology papers should be evaluated keeping this in mind.
} 
experimental work on decision-making procedures has been part of the research agenda in economics. In particular, Plott (1979) started a strand of literature that investigated experimentally how different rules (e.g., open or closed rule) affect committee outcomes. ${ }^{9}$ In general, the richest set of literature studying electoral institutions presents "economics-style," monetarily incentivized laboratory experiments. These studies usually build on clear-cut predictions derived from formal models. When institutional variation in electoral systems is modeled, it is usually a comparison at the most general level of distinguishing among electoral systems, i.e., majoritarian rule, plurality rule, Borda count, or approval voting. The most commonly asked question is about the degree of strategic voting under different electoral rules (Forsythe et al., 1996; Bassi, 2015). Studies also explore turnout (Gschwend and Hooghe, 2008), welfare implications (Bouton, Castanheira and Llorente-Saguer, 2016), minority representation mechanism (Gerber, Morton and Rietz, 1998), or the ability of voters to make "correct" - that is utility maximizing - choices (Blais, Pilet, Van der Straeten, Laslier and Héroux-Legault, 2014b; Blais, St-Vincent, Pilet and Treibich, 2014) when the institutional framework is varied. Morton and Williams (1999) and Battaglini, Morton and Palfrey (2007) derive and test predictions under different electoral institutions, institutions that do not fit the usual terminology of the study of electoral systems. In these articles, subjects behavior under sequential or simultaneous elections are investigated and motivated by variation in the U.S. primary election calendar over the years (Morton and Williams, 1999) or the fact that in one time zone polls already closed while in another time zone in the same U.S. state voting is still going on (Battaglini, Morton and Palfrey, 2007).

\footnotetext{
${ }^{9}$ See McKelvey, Ordeshook et al. (1990) for an overview of this early research on experiments about decision rules within the framework of the spatial model of politics and Fiorina and Plott (1978) for yet another example of an experimental study of the functioning of majority rule in committee decisions.
} 
With respect to results, a question often asked is whether subjects in the laboratory act according to expectations derived from Duverger's law under different electoral rules. ${ }^{10}$ This part of the laboratory-experimental literature is therefore very much in conversation with the observational data literature discussed previously- Duverger is central - even though, interestingly, this relationship is not always reflected in cross-citations. Formal theory is well-placed to spell out precise predictions about strategic behavior - which is the purpose of the language of game theory and testing those predictions on the controlled environment of the laboratory is a logical follow up. In other words, the (laboratory) experimental literature should be a welcomed addition to the "Duvergerian agenda."

One common criticism of laboratory experiments related to electoral systems is incongruences in the context in which decisions are made with those environments in real elections where voters are asked to cast their ballot. While one of the reasons for conducting laborartory experiments in the first place is precisely to "abstract away" from the context of real elections those elements that are theorized not to be important or confounding behavior to be observed, results from the laboratory experiments nevertheless should be subjected to validation of obtained findings in different contexts, including other laboratory studies and studies conducted outside of the laboratory. For instance, Morton et al. (2015) exploit unique features of a particular electoral system, i.e., the fact that polls in French overseas territories close their polls many hours before mainland France starts to vote, while Laslier and co-authors (Laslier and Van der Straeten, 2008; Van der Straeten, Laslier and Blais, 2013) apply the same experimental design as used in the laboratory to broader samples of (online) participants. Combining the controlled setting in the laboratory with external context, Meffert and Gschwend (2011) study voting behavior by exposing subjects to polling information

\footnotetext{
${ }^{10}$ That is, are proporitional rules more likely to yield multiparty systems and majoritarian rules more likely to lead to two-party systems. See Duverger (1954) and Cox (1997) for more details.
} 
and coalition signals from concurrent electoral campaigns. This is a study of how polls and coalition signals affect the prevalence of strategic voting, holding the proportional electoral system constant, but nevertheless illustrates a tool for marrying lab experiments with external context.

It generally needs to be pointed out, though, that to test the precise claims derived from modeling the effect of electoral systems outside of the laboratory requires institutional variation unlikely to be found at a the most general level of distinguishing electoral systems (e.g., proportional vs. majoritarian systems). The variation in incentives at this level is thus often best modeled in the laboratory. As we will show in the next sections on natural and field experiments, there can be, however, exploitable variation in electoral systems at lower levels of the institutional structure in many polities around the world; we show works that make clever use of this variation but many more opportunities are available. ${ }^{11}$

\section{2 "Natural" experiments and close relatives}

Scholars studying electoral systems also have tried to utilize a research design around so called natural (or quasi-) experiments, which tend to take one of two forms. The first, and more common, is to exploit real-world variation in electoral system that is either caused by a random, exogenous shock. The second form is to utilize variation created by a randomization feature built into the electoral system.

With respect to the former, the common approach is to approximate a "natural" experiment in investigating political behavior before and after an electoral reform; studies have taken this approach following reforms in Italy and Japan (Giannetti and Grofman, 2011), Israel (Andersen and

\footnotetext{
${ }^{11}$ By lower level we mean the features of the elector system like the ballot structure, electoral thresholds, electoral formulae or rules governing the electoral enviornment (i.e., candidate selection, campaign finances, polling center allocation, election overesight, appeals processes, ballot format, early voting, etc.), in contrast to the highest level of electoral system, that is, the distinction between majoritarian and proportional systems.
} 
Yaish, 2003), and New Zealand (Vowles, 1995). To be clear, though, in contrast to what the label adopted for these studies suggests, neither the institutional reforms that took place in Italy and Japan in the early 1990s, nor the change from a single-ballot party list to a two ballot system including a direct vote on the Prime Minister in Israel in 1996, nor the shift from a first-past-the-post system to a mixed-member proportional system in New Zealand in 1995, actually involved experimental manipulations. No exogenous shock in nature manipulated any variable of interest, i.e, the institutional framework. Real world legislators changed the electoral system, and they of course had particular reasons for doing so. In many cases, then, the variable of interest can turn out to be endogenous to the politically-induced change, and therefore there may be an unobserved characteristic of these countries that implemented reform that made them susceptible to strive for changing their institution in the first place (which is an example of identification problem rooted in selection). Alternatively, an expected voting pattern may have triggered interest among those in power to change the institutional framework (an example of identification problem rooted in reverse causality).

In any case, while we should perhaps not call such a research design a "natural" experiment, the temporal dimension certainly allows for causal identification of some effects of institutional reform under less restrictive assumptions than findings backed by cross-country correlational evidence. However, interesting institutional variation may be found at lower levels of electoral systems even when using this kind of a "natural experiment" requires "a rather large leap of faith" (Rodden, 2009, 352) in the sense that why institutions assigned to "subjects" (i.e., citizens) should be random is often still a question of how persuaded reader is by the researchers' argument. ${ }^{12}$ Still, it is possible to get around these sorts of concerns if, for example, an electoral reform started as a political stunt seemingly unrelated to such an institutional re-arrangement (Nagel, 2004).

\footnotetext{
${ }^{12}$ See the previous footnote for our definion of "lower levels" of electoral systems.
} 
However, occasionally there are opportunities for researchers to exploit actual randomization processes that are part of the electoral systems and/or are carried out in collaboration with scholars specifically for the purpose of testing the effect of an electoral institution. A range of studies about minority quotas in India (e.g., Chattopadhyay and Duflo (2004); Bhavnani (2009)) provides such robust identification, but for the specific context of the case at hand. Another branch of literature on U.S. state and local elections facilitates the random assignment of candidate names to ballot positions to assess the impact of ballot structure on voters' choices (Koppell and Steen, 2004; Ho and Imai, 2006, 2008; Chen et al., 2014; Pasek et al., 2014).

Finally, Ferwerda (2014) uses the fact that the repeal of compulsory voting in Austrian federal elections happened gradually. Within country variation was created due to the fact that authority over electoral rules shifted between the state and national level several time and the abolishment of fees when failing to turn out spanned more than a decade to reach all constituencies. Of course, there may be some correlation between when the repeal happened and turnout in a given constituency, but the authors argue that the complicated legal process leading to abolishment can be seen as approximating a random assignment of electoral rules.

Studies like the ones on electoral quotas for minorities in India, ballot name ordering, or repeal of compulsory voting epitomize the potential of exploiting variation that is locally concentrated and happens at lower levels of the electoral system. These are great opportunities to grasp, admittedly contextual, effects of electoral institutions on behavior. Nevertheless, generalizable statements about different kinds of electoral systems is more likely - over time - to come from a research agenda of studies exploiting institutional variations in many different contexts and not from a single, ideal experimental design. 


\subsection{Field and survey experiments}

Field experiments strive to test more context-specific hypotheses (Gerber and Green, 2012); one could say they aim for ecological validity (Morton and Williams, 2010, 264). A loss of control, relative to well-designed laboratory experiment, is accepted to observe behavior and elicit attitudes in a richer political environment. How context is created varies widely, and includes such approaches as implementing an experiment while an election takes place, posing as a voter in communicating with politicians, or eliciting subjects' behavior in hypothetical elections.

Shineman (2016) and Bol et al. (2013) are good examples of how to interfere in real voting and candidate behavior through variation in electoral systems. The former uses the occurrence of an actual election, while the latter initiates a response from candidates posing as voter.

Shineman (2016) manipulates the existence of "negative" compulsory voting by randomly assigning a set of self-selected study participants to a treatment that rewards turnout with a gift card. ${ }^{13}$ The author then checks whether the subject actually participates in the election via official vote registers before activating the gift card. ${ }^{14}$ The experiment varies the degree of compulsory voting by rewarding turnout for the treatment group but not for the control group. Bol et al. (2013) vary incentives for a personal vote by priming parliamentarians to consider either their personal skills or their party's platform; these considerations are induced through an email from a fictitious voter who asks the candidate a question about either of the two characteristics. The experimental

${ }^{13}$ By "negative" compulsory voting, we refer to electoral rules that pay people for voting. This is of course from a certain perspective basically equivalent to fining people for not voting, in so far as both sets of rules leave the voter better off financially due to the decision to participate in the election. That being said, a wealth of research exists showing that people value gain and loss differently even when the momentary value is the same, so there is good reason to expect that the effects of "negative" compulsory voting might not generalize to more standard forms of "positive" compulsory voting.

${ }^{14}$ In much of the United States, whether or not people have voted in an election is a matter of public record. 
treatment tries to vary how much a candidate thinks about the single-member district component of the German mixed-member proportional electoral system ("first vote") by priming the opportunity of a personal vote cast by the fictitious voter versus how much a candidate thinks about the partylist element ("second vote") by priming the possibility that the fictitious voter cares about the candidate's party's policies. The authors measure email response rates across treatments. In both examples, researchers observe actual behavior as their outcome variable, but approximate different electoral systems with their randomly assigned experimental treatments. To be sure, some control is lost because candidates in the Bol et al. (2013) study may infer many different things from receiving such an email but not the intended, electoral system-related considerations, and voters in the Shineman (2016) experiment may see the gift card as something other than a negative fine for voting. Nevertheless, the influence of many unobservables that are inherent in the typical crosscountry study of the effect of compulsory voting on turnout and electoral systems on candidates' behavior is muted.

Field experiments require interference in reality often without the a priori knowledge of participants that they are part of an experiment; in the Bol et al. (2013) candidates do not know that the email they received is not from one of their actual constituents, but fictitious. This begs the question of how far should scholars interfere in actual election for the purpose of generating scientific knowledge. The study of electoral systems in particular begs attention to this quesiton, as the consequences of the experimental manipuation could in theory affect the outcome of an election. While such an intervention would have admirable scientific merit, in reality it will often be ethically questionable or legally infeasible. ${ }^{15}$ The two studies described here, then, are also impressive with respect to ethics and feasibility: they manipulate individual-level behavior through a slight

\footnotetext{
${ }^{15}$ One could perhaps call this the "paradox of electoral system field experiments": the more consequential the result of the study is likely to be, the less likely it is to be legally or ethically feasible.
} 
adjustment of the benefits of voting (Shineman, 2016) or priming of candidates (Bol et al., 2013). In other words, both studies exert only a weak influence on the outcome of elections. Both studies still enable themselves to pick up treatment effects because of their direct measurement of the outcome variable (actual vote choice from vote register and email response rate). ${ }^{16}$

However, what happens when we want to broaden the scope of what we are able to say about electoral systems? Questions of feasibility and ethics will undoubtedly arise. With respect to feasibility, collaborations with various governmental and non-governmental actors have proven valuable to gain access to the system or to finance larger experimental manipulations. A prominent example of exploiting a governmental program for research purposes is a design that uses the fact that for receiving development aid, a random selection of villages in Afghanistan were mandated to include women in political decision making (Beath, Christia and Enikolopov, 2013). In this way, suffrage extension is exogenously assigned to some villages but not others. In particular, within a larger development aid project, researchers were able to mandate 125 villages to make decisions based on a council elected in an at-large district while another 125 villages were to elect council members in multiple districts (Beath et al., 2016). To be sure, a project of such scale needs a partner, in this case the government of Afghanistan and multiple NGOs. The abundance of development programs in the world, however, provide many opportunities for such access. For the interested reader, the Beath et al study finds that at-large elections deliver higher average levels of education among council members than district elections with a bias towards locally-targeted public goods.

In considering how to add an experimenter-induced manipulation to one's research design, access and funding are not the only concerns; ethical issues must be addressed as well. A gain in

${ }^{16}$ For full disclosure, one of the authors was a classmate of Shineman's when she worked on this project and the other was a dissertation adviser. Readers should take our praise of her work with appropriate caveats. 
knowledge about the functioning of electoral systems must be balanced against the consequences of potentially changing electoral results. One way to think about this is that great care should be given in considering the potential scope of any induced effect. In many countries, research has to adhere to reviews boards that enforce standards, such as that no harm to subjects may arise from taking part in the study or that the privacy of subjects is to be protected (Morton and Williams, 2010). ${ }^{17}$

However, there does not yet seem to be a clear consensus in the field as to how much interference into elections is too much. To illustrate, a recent attempt to study whether turning a non-partisan electoral system into a partisan system by means of a field experiment received criticism, partly because of the scope of the manipulation. A quarter of the population of the U.S. state of Montana received a leaflet advertising partisan leanings of candidates in a judicial election (Willis, 2014). Due to the scope of the manipulation, there was a perception that the experiment could have changed the outcome of the election. ${ }^{18}$ Explicitly addressing this issue of acceptable levels of impact in field experiments involving election would probably be of benefit to the field in the future.

While the list of survey experiments in political science, including studies that make comparisons across political systems and therefore across electoral systems, has grown to a respectable size, straightforward experimental manipulations of electoral systems are scarce. In those few studies, creating hypothetical elections and observing survey respondents' or experimental subjects' behavior is most common. As examples, Bol et al. (2016) present subjects with a hypothetical vote choice in the European Union parliament election on a hypothetical panEuropean list of candidates; Baujard et al. (2014) ask self-selected subjects to vote upon French

\footnotetext{
${ }^{17}$ That being said, boards focused on protecting subjects may not be tasked with considering the downstream effect of experiments on non-subjects, which can also raise important ethical considerations.

${ }^{18}$ To be clear, there were other factors related to the experiment that also drew the ire of residents of Montanan; see Willis (2014) for additional details.
} 
presidential election candidates during the actual election according to either an approval voting system or an evaluative voting system and compare behavior under those rules to vote choices under the two-round system in place. These experiments are embedded in online surveys and illustrate a very typical operationalization of manipulating electoral systems: asking for behavior and attitudes under different hypothetical electoral systems.

\subsection{Other types of experimental design}

Finally, we conclude with an illustration of other, less common experimental designs aiming to model aspects of electoral systems. Among those are deliberation experiments in the run-up to a reform of British Columbia's electoral system (Warren and Pearse, 2008) and before the 2009 European Parliament election (Isernia and Fishkin, 2014). The Isernia and Fishkin (2014) study involves surveying a representative sample of the European Union population and inviting a random sub-sample to take part in deliberations about issues of the day with other citizens, politicians, and other experts. In a follow-up survey, the researchers elicit voting behavior in the election and political attitudes. In a sense, the election process is experimentally enriched with a deliberation phase to shape subjects' voting decisions. A different question from the influence of a deliberative system on voting behavior is pursued by Warren and Pearse (2008). They report on an initiative by

the Government of British Columbia that installed an assembly of randomly selected citizens to propose changes to the electoral system, which were then put to a vote in front of the general public. Even though no control group exists in this experiment, conveners of the assembly still manipulated the process of electoral reform by modeling variation in the legitimacy of the proposed changes (running from a random sample of citizens instead of a panel of experts or negotiations between political parties). 


\section{Causality and statistical methods}

In political science writ large, experimental research may be the "gold standard" in causal inference, but in many cases an experimental research design may simply not be feasible. For example, no matter how much we might like to know how US elections would turn out under proportional representation rules, the likelihood that a set of states will be randomly assigned to switch to proportional representation for the 2018 US mid-term elections seems unlikely at best. Cognizant of this fact, in recent years scholars have increasingly been using new forms of statistical analysis to attempt to get a better grasp of causal inference even outside of an experimenal research design; such tools include matching, instrumental variables, or regression discontinuity design. These methodological innovations can also be found in the literature on electoral systems.

To give one example, scholars have used "matching" procedures not just in the standard sense of as a statistical estimator. Blais et al. (2011) exploit mixed-member electoral systems which typically give each voter a choice under majoritarian and under proportional rules, permitting scholars to assess the mechanical and psychological effects of electoral institutions on voters and parties. In a sense, this study matches each voter with herself and compares behavior under each of the two electoral rules. Portmann, Stadelmann and Eichenberger (2012) "match" representatives' legislative choices with voters' choices in referenda on the same proposals in Switzerland to estimate the effect of variation in district size on office holders' representativeness of citizens' preferences.

Persson and Tabellini (2005) use propensity score matching of countries as a statistical estimator to understand various economic outcomes associated with differences between majoritarian and proportional electoral rule. Calvo and Micozzi (2005) go down the route of a more 
sophisticated Bayesian estimator, which allows them to match electoral districts in Argentina with respect to partisan bias and majoritarian bias to capture the effects of electoral reforms. ${ }^{19}$

Persson and Tabellini (2005) aim to get at the causal effect of electoral rules on economic outcome using the time of adoption of the country's constitution, the fraction of English speaking or other European language speaking population, and latitude as instrumental variables. To make valid causal claims, a strong instrument should not have an effect on the outcome variable other than the impact through the endogenous regressors. Here, Acemoglu (2005) argues that the time of adoption of the constitution instrument is weak, i.e., only has a weak influence on on the endogenous regressors, and that the language and latitude instruments cannot not be reasonably assumed to be influencing institutional features on theoretical grounds. ${ }^{20}$

Funk and Gathmann (2011) use barriers to launching a referendum on constitutional change in Swiss cantons as an instrument to get at a causal estimate of the effect of referenda on public spending. In this study, the validity of the claim rests on the credibility of the assumption that barriers to launching a referenda affect the existence of the referenda themselves but not the outcome variable, which here is public spending. Finally, Gabel and Scheve (2007) study the effect of elite communication on public opinion instrumenting with institutional changes. Note that this is a different approach to including electoral systems in a study compared to most of those discussed

19 It is important to remember that making valid causal claims based on such a matching procedures requires scholars to make the strong assumption that no omitted variable bias exists, an assumption that is unlikely to be met.

${ }^{20}$ Crisp et al. (2014) also take issue with regular cross-country studies as well as with the instrumental variables approach and implement a vector autoregressive model to capture the endogenous relationship between electoral volatility and legislative corruption; such an approach allows us to learn whether there is a feedback mechanism between the variables of interest but not what the mechanism looks like exactly. Crisp and co-authors claim to show that past perceptions of corruption increase electoral volatility but also that no reverse influence exists. 
previously in this essay: electoral rules are included here not as an explanatory variable, but instead as a device to achieve identification.

Lastly, political science has recently developed a taste for regression discontinuity design. For instance, Dunning and Nilekani (2013) examine the effect of quotas on minority representation and welfare with a study that exploits how reserved districts are assigned. In several Indian states, whether an electoral district is a reserved district is determined by whether it surpasses a certain percentage of district residents being members of the scheduled caste. Dunning and Nilekani use the assumption that districts just above and just below that percentage are indistinguishable in all other characteristics; in this way causal inferences from the comparison of such districts about the effect of imposing quotas on political outcomes can be drawn.

Eggers (2015) takes advantage of the fact that municipal elections in France above certain population thresholds use proportional representation while those below use a plurality rule. Comparing cities around that threshold allows the author to make causal claims about how electoral rules affect turnout. Gagliarducci, Nannicini and Naticchionia (2011) look at Italy, where candidates can run for a seat in parliament in two tiers - a proportional and a majority electoral rule - but have to accept the latter should they win both. For causal claims, they make the assumption that in close election whether a candidate wins none, one, or both tiers is as-if random. What makes this design interesting is the fact that this peculiar electoral institution allows us to compare the behavior of representatives who won under proportional rule against those who picked up a seat under majority rule.

\section{Conclusion}

Let us take it as a given that we want to learn whether electoral systems have a causal effect on some variable of interest. Experimental research provides a tool to do so. It's possible that in some 
instances we may simply be interested in describing a relationship between electoral systems and a paritcular variable of interest, in which case we can do without an experimental manipulation. But, mostly, researchers are interested in causal effects. Also, when we want to know whether a certain variable influences which electoral system emerge, a causality-driven research design is in order. For experimental research to work, researchers need variation - manipulable variation - at the institutional level. Unfortunately, it is unlikely that we will find studies where we can actually randomize the most general level of an electoral system, i.e., whether the system is majoritarian or proportional. But there is constantly variation in other features of electoral systems waiting to be exploited. We argue that this is where field experimental research should move next while experimentalists in general should also continue to do careful, thorough, theory-driven laboratory studies.

Are all questions answerable by experiments? To be sure, the answer to that question is "no." Many questions remain, however, that have not been studied experimentally yet address issues where the institutional variable of interest is open for exogenous manipulation. This could mean a carefully crafted experimental test of a formal model in the laboratory or using "naturally" occurring variation in in reality existing institutions at a lower level of government.

To be clear, we are not recommending that observational data in the study of electoral systems be abandoned - far from it - but we do want to highlight the potential of the experimental method for the field. This is a call to use our broad knowledge about the different, multi-layered features of electoral systems and start exploiting potentially exogenous variation at lower levels of electoral systems or create variation through experimental manipulation that is feasible at those lower levels.

Often, treatment effects estimated from experimental data face biases or do not speak to the question at hand. The former concern is particularly relevant in natural and field experiments where context is specifically invited to play a role in the experiment but comes with confounding factors, 
such as selection bias, attrition, etc. The latter seems to apply more to laboratory experiments testing formal models - there is certainly some truth to this - but experiments in general aim for abstraction that always has to be traded-off against the scope of the claims one can make. A research agenda in any field - like the study of electoral systems and their consequences for political behavior and attitudes - needs balance in all different types of research design. It needs experimental research to enable causal claims but the deep descriptive knowledge of case studies and observational data to understand the scope of the precise treatment effect established. While experimental research may be much newer to the study of electoral systems than the observational research that is present in the classics in the field, we believe the studies described in this essay are already making important contributions to moving the field forward and are likely to continue to do so in the future. 


\section{References}

Acemoglu, Daron. 2005. "Constitutions, politics, and economics: A review essay on Persson and Tabellini's The Economic Effects of Constitutions." Journal of Economic Literature 43(4):1025-1048.

Adams, James, Lawrence Ezrow, Zeynep Somer-Topcu. 2014. "Do Voters Respond to Party Manifestos or to a Wider Information Environment? An Analysis of Mass-Elite Linkages on European Integration." American Journal of Political Science 58(4):967-978.

Alt, James, Ethan Bueno De Mesquita, Shanna Rose. 2011. "Disentangling accountability and competence in elections: evidence from US term limits." The Journal of Politics 73(01):171186.

Andersen, Robert, Meir Yaish. 2003. "Social cleavages, electoral reform and party choice: Israel's "natural" experiment." Electoral Studies 22(3):399-423.

Aytaç, S Erdem. 2014. "Distributive Politics in a Multiparty System The Conditional Cash Transfer Program in Turkey." Comparative Political Studies 47(9):1211-1237.

Bassi, Anna. 2015. "Voting systems and strategic manipulation: An experimental study." Journal of Theoretical Politics 27(1):58-85.

Battaglini, Marco, Rebecca Morton, Thomas Palfrey. 2007. "Efficiency, equity, and timing of voting mechanisms." American political science Review 101(03):409-424.

Baujard, Antoinette, Herrade Igersheim, Isabelle Lebon, Frédéric Gavrel, Jean-François Laslier. 2014. "Who's favored by evaluative voting? An experiment conducted during the 2012 French presidential election." Electoral Studies 34:131-145.

Beath, Andrew, Fotini Christia, Georgy Egorov, Ruben Enikolopov. 2016. "Electoral rules and political selection: theory and evidence from a field experiment in Afghanistan." The Review of Economic Studies 83 (3): 932-968.

Beath, Andrew, Fotini Christia, Ruben Enikolopov. 2013. "Empowering women through development aid: Evidence from a field experiment in Afghanistan." American Political Science Review 107(03):540-557.

Bhavnani, Rikhil R. 2009. "Do electoral quotas work after they are withdrawn? Evidence from a natural experiment in India." American Political Science Review 103(01):23-35.

Blais, André, Jean-Benoit Pilet, Karine Van der Straeten, Jean-François Laslier Maxime HérouxLegault. 2014a. "To vote or to abstain? An experimental test of rational calculus in first past the post and PR elections." Electoral studies 36:39-50.

Blais, André, Romain Lachat, Airo Hino Pascal Doray-Demers. 2011. "The mechanical and psychological effects of electoral systems a quasi-experimental study." Comparative Political Studies 44(12): 1599-1621.

Blais, André, Simon Labbé St-Vincent, Jean-Benoit Pilet Rafael Treibich. 2014b. "Voting correctly in lab elections with monetary incentives The impact of district magnitude." Party Politics 22(4): 544-551.

Bol, Damien, Philipp Harfst, André Blais, Sona N Golder, Jean-François Laslier, Laura B Stephenson Karine Van der Straeten. 2016. "Addressing Europe's democratic deficit: An experimental evaluation of the pan-European district proposal." European Union Politics 17(4):525-545.

Bol, Damien, Thomas Gschwend, Thomas Zittel, Steffen Zittlau. 2013. "The Impact of the Electoral Context on Personal Vote Strategies: A Field Experiment on German Legislators.".

Bouton, Laurent, Micael Castanheira, Aniol Llorente-Saguer. 2016. "Divided majority and information aggregation: Theory and experiment." Journal of Public Economics 134:114-128. 
Calvo, Ernesto, Juan Pablo Micozzi. 2005. “The Governor's Backyard: A Seat-Vote Model of Electoral Reform for Subnational Multiparty Races." Journal of Politics 67(4):1050-1074.

Cantú, Francisco. 2014. "Identifying Irregularities in Mexican Local Elections." American Journal of Political Science 58(4):936-951.

Chattopadhyay, Raghabendra, Esther Duflo. 2004. "Impact of reservation in Panchayati Raj: Evidence from a nationwide randomised experiment." Economic and Political Weekly pp. 979986.

Chen, Eric, Gábor Simonovits, Jon A Krosnick, Josh Pasek. 2014. "The impact of candidate name order on election outcomes in North Dakota." Electoral Studies 35:115-122.

Cho, Seok-Ju. 2014. "Voting equilibria under proportional representation." American Political Science Review 108(02):281-296.

Clark, Michael, Debra Leiter. 2014. "Does the ideological dispersion of parties mediate the electoral impact of valence? A cross-national study of party support in nine western European democracies." Comparative Political Studies 47(2):171-202.

Corazzini, Luca, Sebastian Kube, Michel André Maréchal, Antonio Nicolo. 2014. "Elections and deceptions: an experimental study on the behavioral effects of democracy." American Journal of Political Science 58(3):579-592.

Cox, Gary. 1990. "Centripetal and Centrifugal Incentives in Electoral Systems.” American Journal of Political Science 31:905-35.

Cox, Gary. 1997. Making Votes Count. Cambridge: Cambridge University Press.

Crisp, Brian F, Santiago Olivella, Joshua D Potter, William Mishler. 2014. "Elections as instruments for punishing bad representatives and selecting good ones." Electoral Studies 34:115.

Michael Marsh. 2014. "Confused or competent? How voters use the STV ballot paper." Electoral Studies 34:146-158.

Dinas, Elias, Laura Stoker. 2014. "Age-Period-Cohort analysis: A design-based approach." Electoral Studies 33:28-40.

Dunning, Thad, Janhavi Nilekani. 2013. "Ethnic quotas and political mobilization: caste, parties, and distribution in Indian village councils." American Political Science Review 107(01):35-56.

Duverger, Maurice. 1954. Political Parties: Their Organization and Activity in the Modern State. London: Methuen.

Eggers, Andrew C. 2015. "Proportionality and Turnout Evidence From French Municipalities." Comparative Political Studies 48(2):135-167.

Eggers, Andrew C, Anthony Fowler, Jens Hainmueller, Andrew B Hall, James M Snyder. 2015. "On the validity of the regression discontinuity design for estimating electoral effects: New evidence from over 40,000 close races." American Journal of Political Science 59(1):259-274.

Endersby, James W, Michael J Towle. 2014. "Making wasted votes count: Turnout, transfers, and preferential voting in practice." Electoral Studies 33:144-152.

Ferwerda, Jeremy. 2014. "Electoral consequences of declining participation: A natural experiment in Austria." Electoral studies 35:242-252.

Finseraas, Henning, Kåre Vernby. 2014. "A mixed blessing for the left? Early voting, turnout and election outcomes in Norway." Electoral Studies 33:278-291.

Fiorina, Morris P, Charles R Plott. 1978. "Committee decisions under majority rule: An experimental study." American Political Science Review 72(02):575-598.

Forsythe, Robert, Thomas Rietz, Roger Myerson, Robert Weber. 1996. "An experimental study of voting rules and polls in three-candidate elections." International Journal of Game Theory 25(3):355-383. 
Funk, Patricia, Christina Gathmann. 2011. "Does direct democracy reduce the size of government? New evidence from historical data, 1890-2000.” The Economic Journal 121(557):1252-1280.

Gabel, Matthew, Kenneth Scheve. 2007. "Estimating the effect of elite communications on public opinion using instrumental variables." American Journal of Political Science 51(4):1013-1028.

Gagliarducci, Stefano, Tommaso Nannicini, Paolo Naticchionia. 2011. "Electoral rules and politicians' behavior: a micro test." American Economic Journal: Economic Policy 3(3):144174.

Gans-Morse, Jordan, Sebastian Mazzuca, Simeon Nichter. 2014. "Varieties of clientelism: Machine politics during elections." American Journal of Political Science 58(2):415-432.

Gerber, Alan S Donald P Green. 2012. Field experiments: Design, analysis, and interpretation. WW Norton.

Gerber, Elisabeth R, Rebecca B Morton, Thomas A Rietz. 1998. "Minority representation in multimember districts." American Political Science Review 92(01):127-144.

Giannetti, Daniela, Bernard Grofman. 2011. A natural experiment on Electoral Law reform: evaluating the long run consequences of 1990s electoral reform in Italy and Japan. Vol. 24 Springer Science \& Business Media.

Golder, Matt, Jacek Stramski. 2010. "Ideological congruence and electoral institutions." American Journal of Political Science 54(1):90-106.

González Ocantos, Ezequiel, Chad Kiewiet Jonge, David W Nickerson. 2014. "The Conditionality of Vote-Buying Norms: Experimental Evidence from Latin America." American Journal of Political Science 58(1):197-211.

Grossman, Emiliano, Cornelia Woll. 2014. "Saving the Banks The Political Economy of Bailouts." Comparative Political Studies 47(4):574-600.

Grossman, Guy, W Walker Hanlon. 2014. "Do better monitoring institutions increase leadership quality in community organizations? Evidence from Uganda." American Journal of Political Science 58(3):669-686.

Gschwend, Thomas, Frank Schimmelfennig. 2007. Research Design in Political Science. Springer.

Gschwend, Thomas, Marc Hooghe. 2008. "Should I stay or should I go? An experimental study on voter responses to pre-electoral coalitions." European journal of political research 47(5):556577.

Harada, Masataka, Daniel M Smith. 2014. "You have to pay to play: Candidate and party responses to the high cost of elections in Japan." Electoral Studies 36:51-64.

Hix, Simon. 2004. "Electoral institutions and legislative behavior: Explaining voting defection in the European Parliament." World politics 56(02):194-223.

Ho, Daniel E, Kosuke Imai. 2006. "Randomization inference with natural experiments: An analysis of ballot effects in the 2003 California recall election." Journal of the American Statistical Association 101(475):888-900.

Ho, Daniel E, Kosuke Imai. 2008. "Estimating causal effects of ballot order from a randomized natural experiment the California alphabet lottery, 1978-2002." Public Opinion Quarterly 72(2):216-240.

Isernia, Pierangelo, James S Fishkin. 2014. "The EuroPolis deliberative poll." European Union Politics 15(3):311-327.

Jones, Mark P. 1998. "Gender Quotas, Electoral Laws, and the Election of Women Lessons from the Argentine Provinces." Comparative Political Studies 31(1):3-21.

Kinder, Donald R, Thomas R Palfrey. 1993. Experimental foundations of political science. University of Michigan Press. 
Kolev, Kiril. 2014. "The contingent effect of institutions: Electoral formulas, ethnic polarization, and election quality." Electoral Studies 35:200-214.

Koppell, Jonathan GS, Jennifer A Steen. 2004. "The effects of ballot position on election outcomes." Journal of Politics 66(1):267-281.

Krook, Mona Lena. 2014. "Electoral Gender Quotas A Conceptual Analysis." Comparative Political Studies 47(9):1268-1293.

Kunicova, Jana, Susan Rose-Ackerman. 2005. "Electoral rules and constitutional structures as constraints on corruption." British Journal of Political Science 35(04):573-606.

Laslier, Jean-François, Karine Van der Straeten. 2008. "A live experiment on approval voting." Experimental Economics 11(1):97-105.

Lijphart, Arend. 1971. "Comparative politics and the comparative method." American political science review 65(03):682-693.

Lijphart, Arend. 1994. "Democracies: Forms, performance, and constitutional engineering." European Journal of Political Research 25(1):1-17.

McKelvey, Richard D, Peter C Ordeshook, et al. 1990. "A decade of experimental research on spatial models of elections and committees." Advances in the spatial theory of voting pp. 99144.

Meffert, Michael F, Thomas Gschwend. 2011. "Polls, coalition signals and strategic voting: An experimental investigation of perceptions and effects." European Journal of Political Research 50(5):636-667.

Milesi-Ferretti, Gian Maria, Roberto Perotti, Massimo V Rostagno. 2002. "Electoral Systems And Public Spending." The Quarterly Journal of Economics 117(2):609-657.

Miller, Nicholas R. 2014. "The house size effect and the referendum paradox in US presidential elections." Electoral Studies 35:265-271.

Morton, Rebecca B, Daniel Muller, Lionel Page, Benno Torgler. 2015. "Exit polls, turnout, and bandwagon voting: Evidence from a natural experiment." European Economic Review 77:6581.

Morton, Rebecca B and Joshua A. Tucker. 2014. "Welcome to JEPS", Journal of Experimental Political Science, 1(1): 1-3.

Morton, Rebecca, Kenneth Williams. 1999. "Information Asymmetries and Simultaneous versus Sequential Voting." American Journal of Political Science 93(1):51-67.

Morton, Rebecca, Kenneth Williams. 2010. Experimental Political Science and the Study of Causality. From Nature to the Lab. New York: Cambridge University Press.

Moser, Robert G. 1999. "Electoral systems and the number of parties in postcommunist states." World Politics 51:359-384.

Mozaffar, Shaheen, James R Scarritt, Glen Galaich. 2003. "Electoral institutions, ethnopolitical cleavages, and party systems in Africa's emerging democracies." American political science review 97(03):379-390.

Murray, Rainbow. 2014. "Quotas for men: reframing gender quotas as a means of improving representation for all." American Political Science Review 108(03):520-532.

Nagel, Jack H. 2004. New Zealand: Reform by (nearly) immaculate design. In The Handbook of Electoral System Choice. Springer pp. 530-543.

Neto, Octavio Amorim, Gary W Cox. 1997. "Electoral Institutions, Cleavage Structures, and the Number of Parties." American Journal of Political Science 41(1):149-174.

Norris, Pippa. 2004. Electoral engineering: Voting rules and political behavior. Cambridge University Press. 
Norris, Pippa. 2005. Radical right: Voters and parties in the electoral market. Cambridge University Press.

Otjes, Simon Tom Louwerse. 2014. "Spatial models in voting advice applications." Electoral Studies 36:263-271.

Pasek, Josh, Daniel Schneider, Jon A Krosnick, Alexander Tahk, Eyal Ophir, Claire Milligan. 2014. "Prevalence and moderators of the candidate name-order effect evidence from statewide general elections in California." Public Opinion Quarterly 78(2):416-439.

Persson, Torsten, Gerard Roland, Guido Tabellini, et al. 2007. "Electoral rules and government spending in parliamentary democracies." Quarterly Journal of Political Science 2(2):155-188.

Persson, Torsten, Guido Enrico Tabellini. 2005. The economic effects of constitutions. MIT press.

Persson, Torsten, Guido Tabellini, Francesco Trebbi. 2003. "Electoral rules and corruption." journal of the European Economic Association 1(4):958-989.

Plott, Charles R. 1979. "The application of laboratory experimental methods to public choice.".

Portmann, Marco, David Stadelmann, Reiner Eichenberger. 2012. "District magnitude and representation of the majority's preferences: Evidence from popular and parliamentary votes." Public Choice 151(3-4):585-610.

Powell, G Bingham. 2000. Elections as instruments of democracy: Majoritarian and proportional visions. Yale University Press.

Rodden, Jonathan. 2009. "Endogenous Institutions and Comparative Politics." Comparative politics: Rationality, culture, and structure 333.

Roth, Alvin. 1995. Introduction to Experimental Economics. In The Handbook of Experimental Economics. Princeton University Press pp. 1-110.

Samii, Cyrus. 2016. "Causal Empiricism in Quantitative Research." Available at SSRN .

Schwindt-Bayer, Leslie A, William Mishler. 2005. “An integrated model of women's representation." Journal of Politics 67(2):407-428.

Shineman, Victoria Anne. 2016. "If you mobilize them, they will become informed: experimental evidence that information acquisition is endogenous to costs and incentives to participate." British Journal of Political Science pp. 1-23.

Shugart, Matthew S. 2005. "Comparative electoral systems research: the maturation of a field and new challenges ahead." The politics of electoral systems pp. 25-56.

Shugart, Matthew Soberg. 1995. "The electoral cycle and institutional sources of divided presidential government." American Political Science Review 89(02):327-343.

Spoon, Jae-Jae, Heike Klüver. 2014. "Do parties respond? How electoral context influences party responsiveness.” Electoral Studies 35:48-60.

Taagepera, Rein. 2007. Electoral systems. In Oxford Handbook of Comparative Politics, ed. Susan Stokes. Oxford University Press.

Van de Walle, Nicolas. 2003. "Presidentialism and clientelism in Africa's emerging party systems." The Journal of Modern African Studies 41(02):297-321.

Van der Straeten, Karine, Jean-François Laslier, André Blais. 2013. "Vote au pluriel: how people vote when offered to vote under different rules." PS: Political Science \& Politics 46(02):324328.

Vowles, Jack. 1995. "The politics of electoral reform in New Zealand." International Political Science Review 16(1):95-115.

Warren, Mark E, Hilary Pearse. 2008. Designing deliberative democracy: The British Columbia citizens' assembly. Cambridge University Press. 
Wawro, Gregory J, Ira Katznelson. 2014. "Designing Historical Social Scientific Inquiry: How Parameter Heterogeneity Can Bridge the Methodological Divide between Quantitative and Qualitative Approaches." American Journal of Political Science 58(2):526-546.

Weschle, Simon. 2014. "Two types of economic voting: How economic conditions jointly affect vote choice and turnout." Electoral Studies 34:39-53.

Willis, Derek. 2014. "Professors' Research Project Stirs Political Outrage in Montana." URL: http://www. nytimes. com/2014/10/29/upshot/professors-research-project-stirspoliticaloutrage-in-montana. html .

Wilson, Matthew C. 2014. "A Discreet Critique of Discrete Regime Type Data." Comparative Political Studies 47(5):689-714. 